\title{
Frauen in Führungspositionen
}

Der djb setzt sich seit Jahrzehnten dafür ein, dass sich der Anteil von Frauen in Führungspositionen der Wirtschaft erhöht. Viel hat sich dafür in den vergangenen Monaten getan.

Einen Überblick über den politischen Werdegang in Hinblick auf die gesetzliche Einführung einer Frauenquote für Aufsichtsräte börsennotierter Unternehmen in Deutschland und Europa gibt Katrin Lange, Projektmitarbeiterin des djb. Das unermüdliche Engagement von EU-Justizkommissarin Viviane Reding auf europäischer Ebene und von Jana Schiedek, Hamburger Senatorin für Justiz und Gleichstellung, auf der nationalen Ebene hat die strukturelle Benachteiligung von Frauen an Führungspositionen in der Wirtschaft dauerhaft in den Fokus der medialen Berichterstattung gerückt.

Am 28. November 2012 wurde im Allianz Forum, Berlin die Studie 2012 „Aktionärinnen fordern Gleichberechtigung - Ziele, Strategien und Maßnahmen für mehr Frauen in Führungspositionen“ präsentiert. Sie erscheint bereits zum dritten Mal in Folge und enthält die Auswertung der Antworten auf unsere Fragen nach den Zielen der Unternehmen, ihren Strategien und konkreten Maßnahmen zur Gewinnung weiblicher Führungs- kräfte, Aufsichtsräte und Vorstände. Nach der inhaltlichen Vorstellung der Studie durch djb-Präsidentin Ramona Pisal folgten weitere starke Statements prominenter Rednerinnen. Die Reden von Renate Augstein, Ministerialdirektorin und Leiterin der Abteilung Gleichstellung, Chancengleichheit im BMFSFJ, Prof. Bascha Mika, Publizistin und Mitglied von ProQuote Medien e.V. und Ana-Cristina Grohnert, Managing Partner People für Deutschland, Schweiz und Österreich der Ernst \& Young GmbH sind in diesem Heft abgedruckt. Darüber hinaus stellt Prof. Dr. Carsten Wippermann von der Katholischen Stiftungsfachhochschule in München kurz die Kernergebnisse seiner Studie zu Personalberatungen und deren Rolle bei der Besetzung von Führungspositionen vor.

Am 27. März 2013 lud die Regionalgruppe Brüssel im djb zum Thema „Frauen in Führungspositionen - Kommt die ,europäische' Quote?“ in die Vertretung des Freistaates Bayern bei der Europäischen Union ein. Der dort von djb-Präsidentin Ramona Pisal gehaltene Vortrag ist ebenfalls in dieser Ausgabe abgedruckt und resümiert den aktuellen Stand zum Thema. (KL)

\section{Was bisher geschah: \\ Das Ringen um die gesetzliche Regelung einer Frauenquote in wirtschaftlichen Führungspositionen}

\author{
Katrin Lange \\ Projektmitarbeiterin, Deutscher Juristinnenbund, Berlin
}

Die Diskussion über eine chancengleiche Beteiligung von Frauen in Führungspositionen börsennotierter Unternehmen hat im vergangenen Jahr durch Gesetzesinitiativen in Deutschland und Europa einen fulminanten Auftrieb bekommen. Zeit, um auf diese Entwicklung einen Blick zu werfen:

Im März 2012 lief die von EU-Justizkommissarin Viviane Reding gesetzte Frist ab, innerhalb derer sich börsennotierte europäische Unternehmen freiwillig verpflichten konnten, einen Frauenanteil von 30 Prozent bis 2015 bzw. 40 Prozent bis 2020 in den Vorständen und Aufsichtsräten zu erreichen. Ihr Aufruf „Frauen in den Chefetagen - Selbstverpflichtung für Europa “1 startete ein Jahr zuvor als eine der ersten Maßnahmen der EU in diesem Bereich. Trotz Appelle der Kommission, des Parlaments und vereinzelt auch von Ministern des Rates für Beschäftigung und Soziales, unterschrieben lediglich 24 Unternehmen, darunter keines aus Deutschland, diese Selbstverpflichtung.

Parallel zur Veröffentlichung des Fortschrittsberichtes „Frauen in wirtschaftlichen Entscheidungspositionen in der EU“2 und als Konsequenz angekündigter Handlungsschritte startete die Europäische Kommission eine öffentliche Konsultation zum „unausgewogenen Geschlechterverhältnis in den höchsten Entscheidungsgremien von Unternehmen in der EU“.3 Insgesamt nahmen fast 500 Einzelpersonen, Interessenverbän- de, Parteien, Unternehmen und Regierungen auf nationaler, regionaler und kommunaler Ebene, ${ }^{4}$ darunter auch der djb, ${ }^{5}$ teil. Gegenstand war die Bewertung der gegenwärtig aus unverbindlichen Maßnahmen bestehenden Situation sowie die Diskussion möglicher Lösungsansätze und ihrer Folgenabschätzung. Auch die Bundesregierung beteiligte sich mit einer Stellungnahme an der Konsultation und verwies mit Nennung der Förderung des Projektes „Aktionärinnen fordern Gleichberechtigung“ auf die Vielzahl von Maßnahmen, die jenseits gesetzlicher Regelungen notwendige Veränderungsprozesse in der Wirtschaft anstoßen. Unter der Berücksichtigung des in der EU geltenden Subsidiaritätsprinzips erklärte die Bundesregierung, „Maßnahmen auf freiwilliger und ggf. gesetzlicher Basis zur Begleitung der freiwilligen Zielvereinbarungen [...] zur Steigerung des Anteils von Frauen in Vorständen und Aufsichtsräten“ prüfen zu wollen.

Nach Ablauf der Konsultation wurde Mitte Juni bekannt, dass Viviane Reding eine Gesetzesinitiative plant, europaweit

1 <http://ec.europa.eu/commission 2010-2014/reding/ womenpledge/index_en.htm> (Zügriff: 11.3.2013).

2 <http://ec.europa.eu/justice/newsroom/gender-equality/opinion/ files/120528/women_on_board_progress_report_de.pdf $>$ (Zugriff: 11.3.2013).

3 <http://ec.europa.eu/justice/newsroom/gender-equality/ opinion/120528_de.htm> (Zugriff: 6.3.2013).

4 <http://eur-lex.europa.eu/LexUriServ/LexUriServ.do?uri=COM:2012 :0614:FIN:de:PDF> (Zugriff: 6.3.2013).

5 <http://www.djb.de/Kom/K5/st12-5/> (Zugriff: 6.3.2013). 